\title{
De novo production of the flavonoid naringenin in engineered Saccharomyces cerevisiae
}

Frank Koopman ${ }^{1,2,3}$, Jules Beekwilder ${ }^{2,4,5}$, Barbara Crimi ${ }^{1,2,3}$, Adele van Houwelingen ${ }^{4}$, Robert D Hall ${ }^{2,4,5}$, Dirk Bosch ${ }^{2,4,5}$, Antonius JA van Maris ${ }^{1,3}$, Jack T Pronk ${ }^{1,2,3}$ and Jean-Marc Daran ${ }^{1,2,3^{*}}$

\begin{abstract}
Background: Flavonoids comprise a large family of secondary plant metabolic intermediates that exhibit a wide variety of antioxidant and human health-related properties. Plant production of flavonoids is limited by the low productivity and the complexity of the recovered flavonoids. Thus to overcome these limitations, metabolic engineering of specific pathway in microbial systems have been envisaged to produce high quantity of a single molecules.

Result: Saccharomyces cerevisiae was engineered to produce the key intermediate flavonoid, naringenin, solely from glucose. For this, specific naringenin biosynthesis genes from Arabidopsis thaliana were selected by comparative expression profiling and introduced in S. cerevisiae. The sole expression of these $A$. thaliana genes yielded low extracellular naringenin concentrations $(<5.5 \mu \mathrm{M})$. To optimize naringenin titers, a yeast chassis strain was developed. Synthesis of aromatic amino acids was deregulated by alleviating feedback inhibition of 3-deoxy-d-arabinose-heptulosonate-7-phosphate synthase (Aro3, Aro4) and byproduct formation was reduced by eliminating phenylpyruvate decarboxylase (Aro10, Pdc5, Pdc6). Together with an increased copy number of the chalcone synthase gene and expression of a heterologous tyrosine ammonia lyase, these modifications resulted in a 40-fold increase of extracellular naringenin titers (to approximately $200 \mu \mathrm{M}$ ) in glucose-grown shake-flask cultures. In aerated, pH controlled batch reactors, extracellular naringenin concentrations of over $400 \mu \mathrm{M}$ were reached.

Conclusion: The results reported in this study demonstrate that $S$. cerevisiae is capable of de novo production of naringenin by coexpressing the naringenin production genes from $A$. thaliana and optimization of the flux towards the naringenin pathway. The engineered yeast naringenin production host provides a metabolic chassis for production of a wide range of flavonoids and exploration of their biological functions.
\end{abstract}

Keywords: Saccharomyces cerevisiae, Naringenin, de novo, Flavonoids, Metabolic engineering

\section{Background}

In recent years, plant flavonoids, which comprise a family of over 9000 compounds, have attracted a tremendous increase in research interest [1-3]. This interest is mainly attributed to highly promising human health applications of specific flavonoids [4-8]. The biological activities of flavonoid compounds have been investigated in relation to a multitude of human pathological conditions, including cancer, diabetes, obesity and Parkinson's disease [6,9-14].

\footnotetext{
* Correspondence: j.g.daran@tudelft.nl

'Department of Biotechnology, Delft University of Technology, Julianalaan 67, 2628 BC Delft, the Netherlands

2Platform for Green Synthetic Biology, P.O. Box 5057, 2600 GA Delft, The Netherlands

Full list of author information is available at the end of the article
}

The identified mechanisms of action include scavenging of oxygen radicals, anti-inflammatory, antiviral and antitumor activities $[15,16]$.

Both for health related research and commercial nutritional applications, availability of sufficient amounts of defined flavonoid preparations is important. To date, flavonoid production mostly relies on isolation from plants. However, investigation and subsequential industrialization from plants is hampered by their low production efficiency. In addition to the low growth rate of some of the producing plants, extraction and separation of flavonoids with highly related structures complicate plant-based production, thereby impeding progress in the exploration of the biological activities of flavonoids [13,14]. Although flavonoids can be produced chemically, efficient production

\section{Biomed Central}


of flavonoids by organic synthesis is severely hindered by the complexity of the molecules, as well as by the necessity of utilizing toxic chemicals and extreme reaction conditions [13,14].

In response to the poor production efficiency from plants and chemical synthesis, research groups have directed their attention to the heterologous production of flavonoids in microorganisms such as Escherichia coli and Saccharomyces cerevisiae, using metabolic engineering and synthetic biology [14,17-20]. In plants, formation of the central metabolite naringenin involves six steps catalyzed by phenylalanine ammonia lyase $(P A L)$, cinnamate 4-hydroxylase $(\mathrm{C} 4 \mathrm{H})$ and its associated cytochrome P450 reductase $(C P R)$, 4-coumaric acid-CoA ligase (4CL), chalcone synthase $(\mathrm{CHS})$ and chalcone isomerase $(\mathrm{CHI})$ (Figure 1) [21,22]. Alternatively, a tyrosine ammonia lyase (TAL) can convert tyrosine directly to coumaric acid and circumvent the use of membrane bound P450 related enzymes, which may pose challenges in $E$. coli $[14,18]$. Additionally, in plants, these enzymes and their corresponding genes are often represented by several isoforms, which may differ in substrate preference or kinetic properties [23]. Moreover, the different isoforms are proposed to be organized in one or more enzyme complexes that may promote substrate channeling. In Arabidopsis thaliana, interaction between $\mathrm{CHS}, \mathrm{CHI}$ and an enzyme downstream of naringenin, flavonol 3-hydroxylase were demonstrated based on affinity chromatography and immunoprecipitation assays [24-26].

Expression of enzyme combinations, originating from a variety of host organisms has yielded microbial strains capable of producing the key flavonoid precursor naringenin (Figure 1). Several reports describe successful biotransformation processes in which a phenylpropanoid precursor, such as coumaric acid, is converted into naringenin by metabolically engineered $E$. coli or S. cerevisiae $[1,14,17,19,20,27,28]$. The highest naringenin titers obtained through biotransformation were achieved in $E$. coli, with naringenin titers reaching $1.74 \mathrm{mM}$ (474 $\mathrm{mg} \cdot \mathrm{l}^{-1}$ ) from $2.6 \mathrm{mM}$ coumaric acid supplied to the medium [1]. The reliance on 'expensive' phenylpropanoid precursors might represent a major hurdle for economically feasible flavonoid production[18]. Hitherto, only one study reports de novo naringenin production from glucose. Using an engineered $E$. coli strain, naringenin titers of up to $106.5 \mu \mathrm{M}\left(29 \mathrm{mg} \cdot \mathrm{l}^{-1}\right)$ were obtained [18].

S. cerevisiae has several attractive characteristics as a metabolic engineering platform for flavonoid production. In addition to its excellent accessibility to molecular and synthetic biology techniques $[29,30]$, its eukaryotic nature may facilitate functional expression of plant-derived flavonoid-biosynthetic genes. For example, S. cerevisiae can functionally express cytochrome P450-containing enzymes and its subcellular compartmentation is comparable to that of plant cells [31]. Finally, its GRAS (generally recognized as safe) status facilitates subsequent application for the production of pharma- and nutraceuticals.

The goal of the present study was to define a metabolic engineering strategy for de novo production of naringenin by S. cerevisiae, using glucose as sole carbon source. For optimal synergistic activity, the flavonoid biosynthetic genes PAL1, C4H, CPR1, 4CL3, CHS3 and CHI1 used in this study were derived from a single plant species, A. thaliana and selected for in planta co-expression profiles. After expression of the plant pathway genes, optimization of naringenin production was explored by engineering of precursor supply to the naringenin pathway and by reducing the formation of byproducts derived from yeast metabolism.

\section{Results}

\section{Selection of naringenin biosynthetic genes from A. thaliana}

As a first step towards heterologous expression of naringenin in S. cerevisiae, flavonoid biosynthetic genes were selected from $A$. thaliana. It has been proposed that, in plants, flavonoid biosynthetic enzymes can be organized in protein complexes, where the proteins involved in the pathway are spatially co-localized. The combination of isoenzymes in such complexes is hypothesized to facilitate the synthesis of different flavonoids [24]. In addition, complex formation might enhance pathway activity and carbon flux via metabolic channeling of intermediates [24]. Moreover, formation of toxic intermediates is kept locally and are sequentially converted [32]. Protein complex formation is likely to require specific protein-protein interactions and therefore, co-evolution of the protein structures of the enzymes that form these complexes. In A. thaliana, several isoenzymes exist for most of the reactions leading to naringenin formation (Table 1). In order to identify the best set of isoenzymes for naringenin production and maintain the potential benefit of plant-specific protein-protein interactions upon expression in S. cerevisiae, a subset of isoenzymes from one single species, $A$. thaliana, was identified and subsequently subjected to expression profile correlation analysis. The subset of isoenzymes was selected based on previous reports indicating either the involvement in the lignin biosynthetic pathway [33] and/or the flavonoid biosynthetic pathway (Figure 1), since these pathways share the same reactions up to the metabolic branch-point coumaroyl-CoA. The specific genes from this isoenzyme subset were then further assessed for the correlation of their expression levels in a dataset comprising 392 transcriptome studies of $A$. thaliana [34].

From the expression correlation analysis, using the BAR Expression Angler [35], two clear modules could be distinguished (Figure 2). The first module comprises 


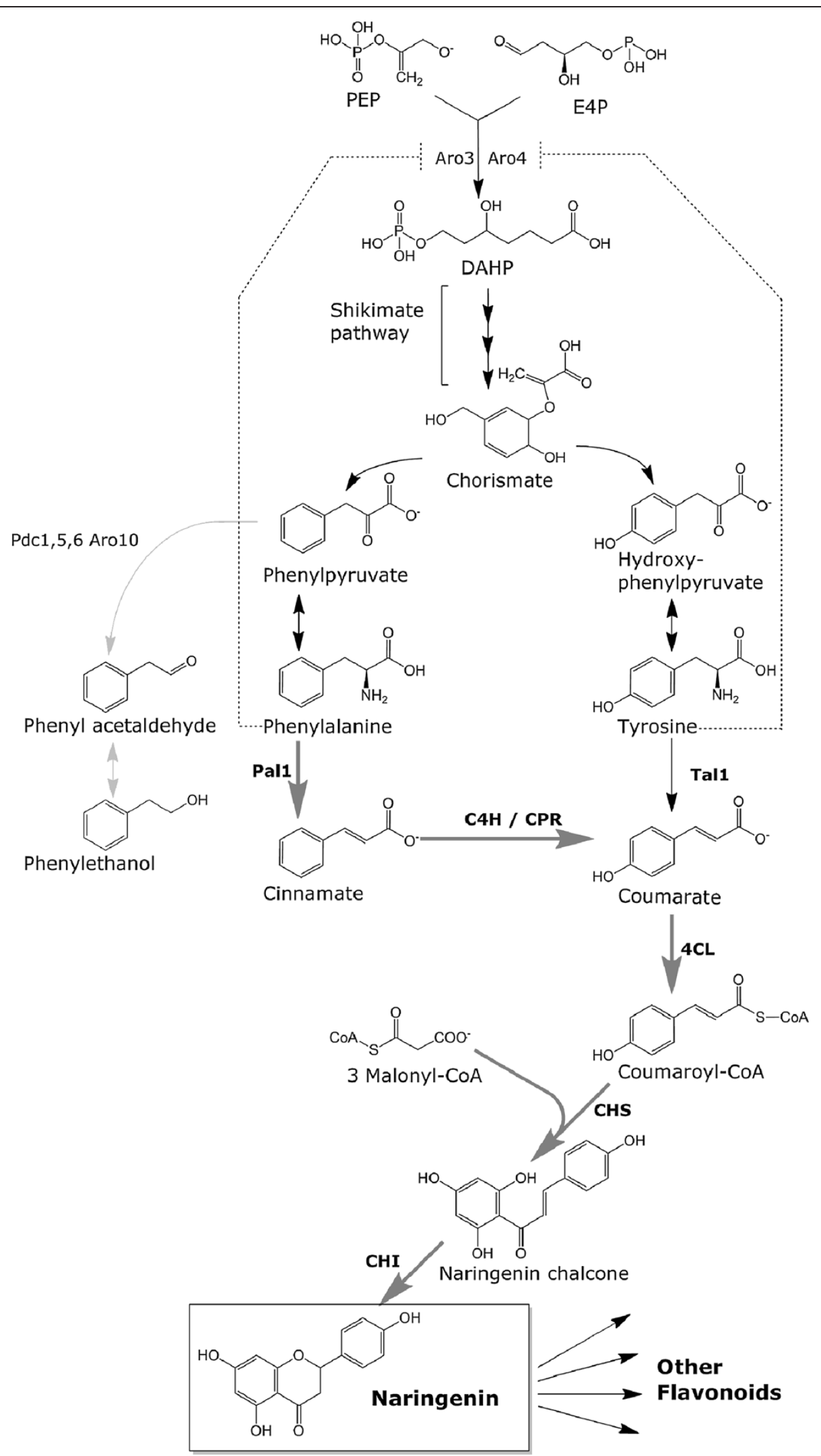

Figure 1 (See legend on next page.) 
(See figure on previous page.)

Figure 1 Schematic representation of the engineered naringenin production pathway in S. cerevisiae. Six $A$. thaliana genes were overexpressed: PAL1 (phenylalanine ammonia lyase), C4H (Cinnamate 4-hydroxylase), CPR1 (cytochrome P450 reductase), 4CL3 (4-coumaric acid-COA ligase), CHS3 (chalcone synthase) and CHI1 (chalcone isomerase), and one gene from Rhodobacter capsulatus; Tal1 (tyrosine ammonia lyase). Dashed lines indicate feedback inhibition. Grey arrows indicate the S. cerevisiae pathway for phenylethanol production. Bold dark grey arrows indicate the naringenin production pathway as described for A. thaliana [22]. Aro3/Aro4: 3-deoxy-D-arabino-heptulosonate-7-phosphate (DAHP) synthase, Pdc1, 5, 6; pyruvate decarboxylases, Aro10; phenylpyruvate decarboxylase.

flavonoid biosynthetic genes, including the 4-coumaric acid-CoA ligase gene (4CL3), the chalcone synthase gene (CHS3), two chalcone isomerase genes (CHI1, CHI3) and a number of genes that mediate the further modification of naringenin. The second, a lignin module, comprised two phenylalanine ammonia lyase (PAL1, PAL2) genes, the trans-cinnamate 4-monooxygenase $(C 4 H)$ gene and three 4-coumaric acid-CoA ligase genes (4CL1, 4CL2, $4 C L 4$ ), in addition to a number of genes known to be involved in formation of lignin and phenolic esters.

Since these results are in good agreement with a previous study on expression correlation in plants [36], the following genes for the pathway towards naringenin were selected for heterologous expression in S. cerevisiae: the flavonoid biosynthetic genes 4CL3 (at1g65060), CHS1 (at4g00040) and CHI1 (at5g05270), as well as, C4H (at2g30490) and PAL1 (at2g37040) from the lignin

Table 1 A. thaliana genes included in the expression correlation studies

\begin{tabular}{lll}
\hline Gene & Gene product & A. thaliana locus \\
\hline PAL1 & phenylalanine ammonia lyase & at2g37040 \\
PAL2 & phenylalanine ammonia lyase & at3g53260 \\
PAL3 & phenylalanine ammonia lyase & at5g04230 \\
PAL4 & phenylalanine ammonia lyase & at3g10340 \\
C4H & trans-cinnamate 4-monooxygenase & at2g30490 \\
4CL1 & 4-coumaric acid-CoA ligase & at1g51680 \\
4CL2 & 4-coumaric acid-CoA ligase & at3g21240 \\
4CL3 & 4-coumaric acid-CoA ligase & at1g65060 \\
4CL4 & 4-coumaric acid-CoA ligase & at3g21230 \\
CHS1 & Chalcone synthase & at4g00040 \\
CHS2 & Chalcone synthase & at4g34850 \\
CHS3 & Chalcone synthase & at5g13930 \\
CHI1 & Chalcone isomerase & at5g05270 \\
CHI2 & Chalcone isomerase & at3g63170 \\
CHI3 & Chalcone isomerase & at3g55120 \\
F3H & Flavanone 3-hydroxylase & at3g51240 \\
FLS & Flavonol synthase & at5g08640 \\
HCT & Quinate O-hydroxycinnamoyltransferase & at5g48930 \\
CCOOMT & Caffeoyl-CoA 3-O-methyltransferase & at4g34050 \\
C3H & p-coumaric acid 3-hydroxylase & at2g40890
\end{tabular}

Bold letters indicate genes used in the construction of engineered S. cerevisiae strains. biosynthetic genes [37]. PAL1 and CHI1 were preferred over PAL2 and CHI3, as their expression profiles showed stronger correlations with $C 4 H$ and $4 C L 3$ respectively (Figure 2).

\section{Construction and evaluation of a naringenin producing strain}

To enable naringenin production in S. cerevisiae, one episomal and one integrative expression vector were constructed which together, harbor the five flavonoid biosynthetic genes. Additionally, activation of the cytochrome $\mathrm{P} 450 \mathrm{C} 4 \mathrm{H}$ requires a cytochrome $\mathrm{P} 450$ reductase $(C P R)$. To choose the best candidate gene, the two A. thaliana $C P R$ variants (CPR1 or CPR2) were separately included in the pathway engineering strategy. First, the centromeric

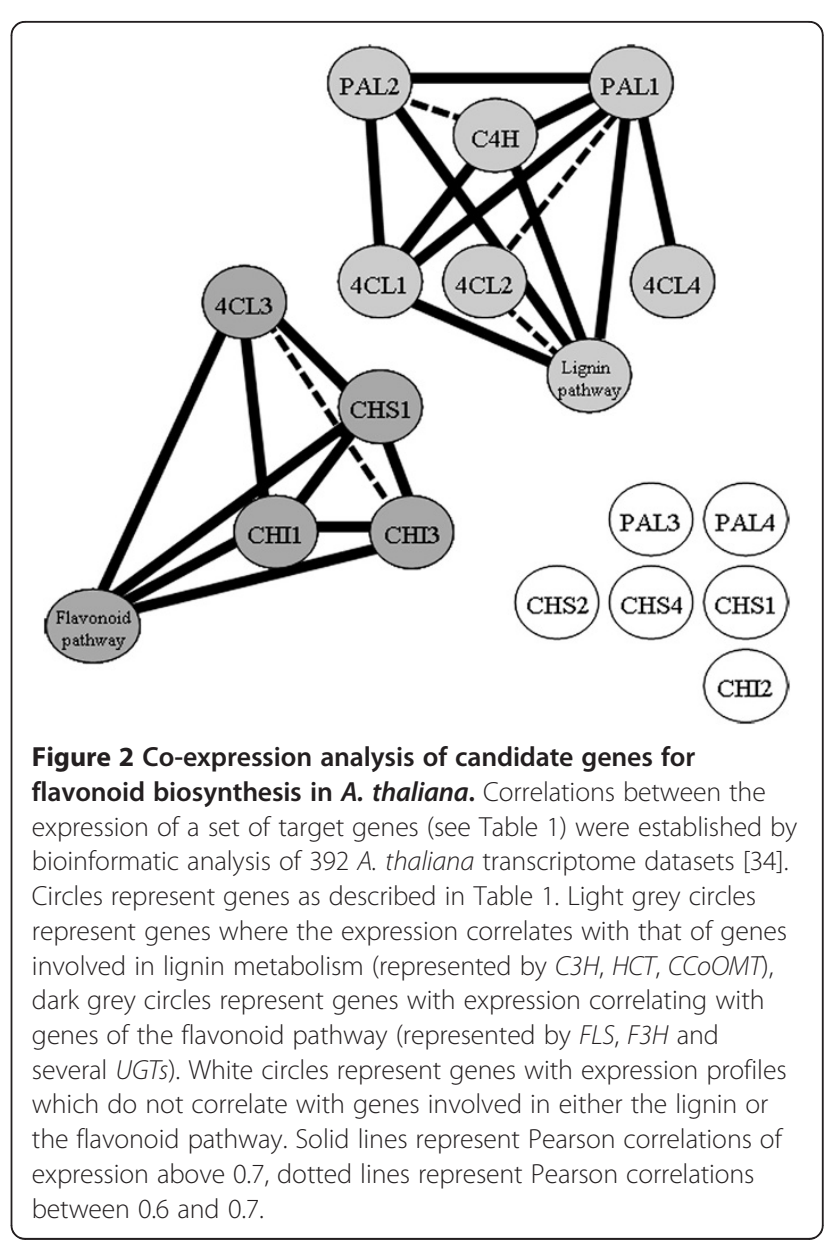


episomal plasmid pUDE172, carrying PAL1 and yeast codon-optimized versions of the $A$. thaliana $C 4 H$ (coC4H) and CPR1 (coCPR1) genes was constructed. In a same manner, separate construct, $P A L 1$ and $c o C 4 H$ were combined with the $C O C P R 2$ gene. Subsequently, the integration plasmid pUDI065 was constructed, which carried the non yeast optimized A. thaliana genes at4CL3, atCHS1 and atCHI1. Only the, C4H and CPR1 in the naringenin production pathway were codon optimized since these genes hold the majority of rare codons for yeast (8), compared to the other genes (PAL1, 4CL3, CHS3 and CHI1) (3). When coCPR2 was expressed instead of coCPR1, significantly lower naringenin titers were observed (data not shown); $c o C P R 2$ was therefore not used in further experiments. Introduction of the CoCPR 1 version of the centromeric expression vector and the integration vector yielded the $S$. cerevisiae strain IMU011. In shake-flask cultures containing synthetic medium and with glucose as the sole carbon source, this strain produced naringenin to a concentration of $5.4 \mu \mathrm{M}$ (Figure 3A). Interestingly, naringenin was measured extracellularly, although its export mechanism has not yet been elucidated.

\section{Alleviation of tyrosine feedback inhibition of yeast 3-deoxy-D-arabinose-heptulosonate-7-phosphate (DAHP) synthase}

Since phenylalanine is a key intermediate in naringenin biosynthesis (Figure 1), further metabolic engineering was directed at improving its intracellular availability. Aromatic amino acid biosynthesis in S. cerevisiae is subject to strong feedback inhibition by phenylalanine and tyrosine. Introduction of a tyrosine insensitive $A R O 4$ allele $\left(A R O 4^{G 226 S}\right)[38,39]$ in conjunction with the deletion of the other allele of the 3-deoxy-d-arabinose-heptulosonate7-phosphate (DAHP) synthase (ARO3) has previously been shown to cause a 4-fold increase in flux through the aromatic amino acid pathway [40]. To test the potential impact of this genetic intervention on naringenin synthesis,

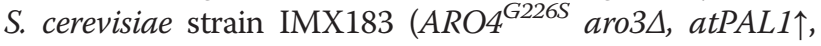

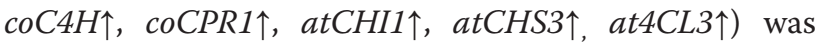
constructed. The deregulation of DAHP synthase in this strain lead to a 2-fold increase of the naringenin titer in shake flask cultures $(10.4 \mu \mathrm{M})$ (Figure 3). However, this increase was accompanied by a strongly enhanced accumulation of phenylethanol, whose extracellular concentration was increased 100-fold to a level ca. 20 fold higher than the improved naringenin concentration (Figure 3B). Therefore, to improve further naringenin production, we adopted a strategy to reduce the diversion of aromatic amino acid biosynthesis into this byproduct.

\section{Elimination of competing phenylpyruvate decarboxylase activity}

In S. cerevisiae, phenylethanol is produced via the Ehrlich pathway. Decarboxylation of phenylpyruvate, the 2-oxo acid associated to phenylalanine, yields phenylacetaldehyde, which is subsequently reduced into phenylethanol and/or oxidized to phenylacetate [41-43]. Decarboxylation of phenylpyruvate can be catalyzed by four different thiamine pyrophosphate-dependent 2-oxo acid decarboxylases encoded by $A R O 10, P D C 1, P D C 5$, and PDC6 $[43,44]$. Recent work in our group has demonstrated that, among the four decarboxylases capable of phenylpyruvate decarboxylase, Pdc1 and Pdc6 showed a much lower affinity and decarboxylation rate of phenylpyruvate than Pdc5 and, in particular, Aro10 [44]. Since absence of all three pyruvate decarboxylase genes (PDC1, PDC5 and $P D C 6)$ abolishes growth on glucose in synthetic media, strains only retaining PDC1 (aro10 $\Delta$, pcd5 5 , pdc6 6 ) were constructed [45]. The intermediate strain IMX185 $\left(A R O 4^{G 226 S}\right.$, aro3 $\left.\Delta, p d c 5 \Delta, p d c 6 \Delta\right)$ did not show a reduced phenylethanol titer compared to its ancestor IMX183 (ARO4 ${ }^{G 226 S}$, aro3A) (Figure 3B). In contrast, the
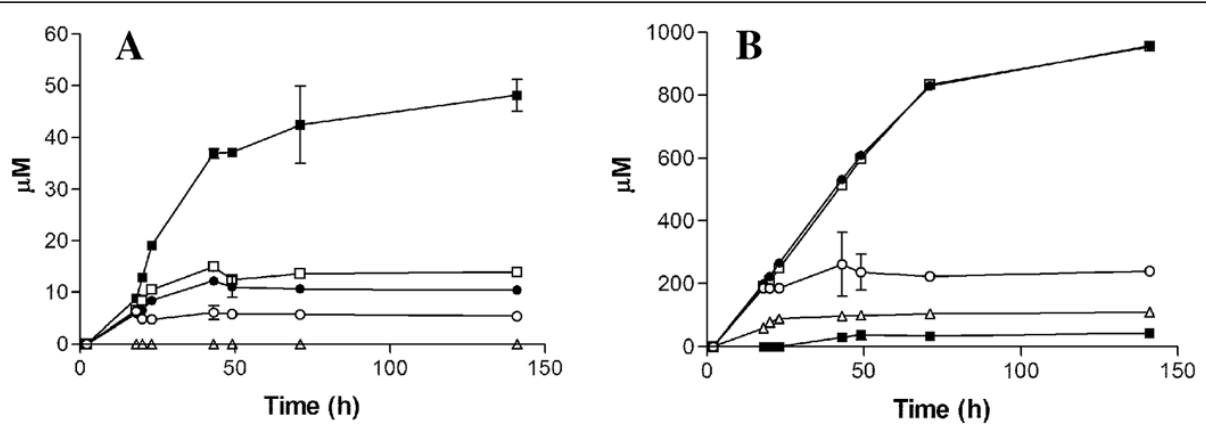

Figure 3 Naringenin production in S. cerevisiae. A) Increase in heterologous production of naringenin. B) Phenylethanol production in

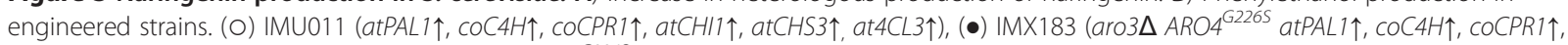

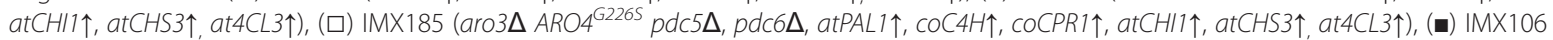
(aro3 $\triangle A R O 4^{G 226 S}$ aro $\left.10 \Delta, p d c 5 \Delta, p d c 6 \Delta, a t P A L 1 \uparrow, \operatorname{coC} 4 H \uparrow, \operatorname{coCPR} 1 \uparrow, \operatorname{atCH} 11 \uparrow, \operatorname{atCHS3} \uparrow, a t 4 C L 3 \uparrow\right),(\Delta)$ non-naringenin producing reference strain CEN.PK2-1C. Cultures were grown in shake flasks on synthetic medium containing $20 \mathrm{~g} \cdot{ }^{-1} \mathrm{glucose}$ and appropriate growth factors to supplement the auxotrophic requirements of the strains. All cultures were performed in triplicate. Error bars denote standard deviation. 
naringenin producing strain IMX106 $\left(A R O 4^{G 226 S}\right.$, aro3A, $p d c 5 \Delta, p d c 6 \Delta$, aro10 $)$ that also carries the ARO10 deletion exhibited a 22-fold lower concentration of extracellular phenylethanol $(44 \mu \mathrm{M})$ compared to both ancestor strains IMX183 and IMX185 (955 $\mu \mathrm{M})$. This strong reduction in phenylethanol production coincided with a 3-fold increase of extracellular naringenin (up to $46.5 \mu \mathrm{M}$ ) (Figure 3A), indicating that reduction of the flux through the Ehrlich pathway had indeed led to substantial improvement in naringenin production. Analysis of culture supernatants revealed that strain IMX106 also produced coumaric acid up to a concentration of $200 \mu \mathrm{M}$ (Figure 4). Moreover, this strain showed increased production of another aromatic metabolite that, based on HPLC spectra and LC-MS analysis, was identified as phloretic acid (Figure 4). Production of phloretic acid was only observed in cultures that also produced coumaric acid and which expressed 4CL3 (data not shown). This suggests that phloretic acid is most likely produced from coumaroyl-CoA (Figure 4).

\section{Alleviate the bottleneck downstream of coumaric acid} Naringenin chalcone synthase, which catalyzes the formation of chalcone by condensing coumaroyl-CoA with three molecules of malonyl-CoA, is known to be an enzyme with low catalytic activity [46]. The transient accumulation and later reconsumption of coumaric acid in shake flask cultures suggested that reactions downstream of coumaric acid were limiting naringenin production. To test whether the capacity of chalcone synthase was indeed controlling flux through the pathway, two additional copies of the coCHS3 gene were introduced into strain IMX106 on an episomal plasmid (pUDE188),

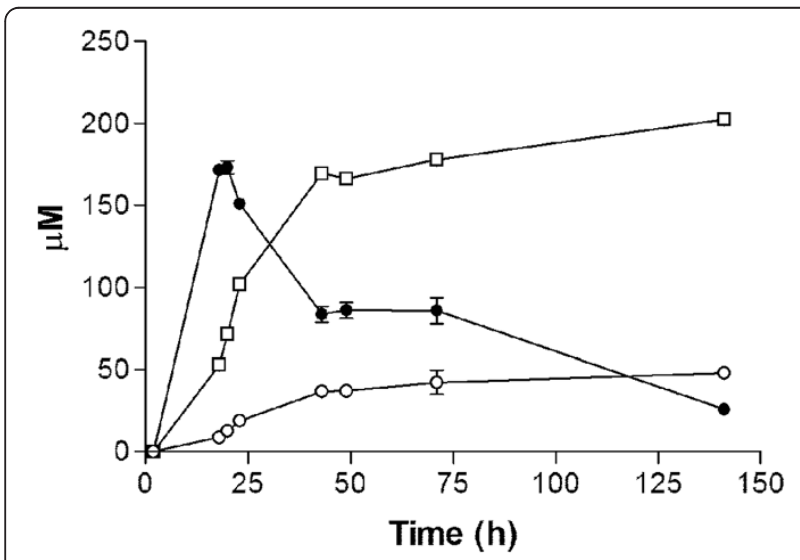

Figure 4 Product formation by S. cerevisiae IMX106 (aro3 $\Delta$ $A R O 4^{G 2265}$ aro $10 \Delta, p d c 5 \Delta, p d c 6 \Delta$, atPAL $1 \uparrow, c 0 C 4 H \uparrow, c 0 C P R 1 \uparrow$,

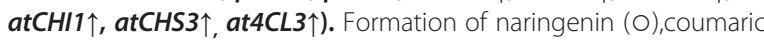
acid $(\bullet)$ and phloretic acid $(\square)$. Cultures were grown in shake flasks on synthetic medium containing $20 \mathrm{~g}^{-l^{-1}} \mathrm{glucose}$. All cultures were performed in triplicate. Error bars denote standard deviation. yielding strain IMX197. The two additional copies resulted in a 2.5 fold increase in naringenin accumulation $(134.5 \mu \mathrm{M})$ in shake flask cultures (Figure 5A), indicating that $c o C H S 3$ was indeed a limiting step in the naringenin production. Additional coCHS3 copies also caused a decreased production of phloretic acid (Figure 5B), consistent with the hypothesis that phloretic acid production occurs when coumaroyl-CoA cannot be efficiently converted to naringenin.

\section{Expression of a tyrosine ammonia lyase leads to increased naringenin synthesis}

The engineered naringenin production pathway directs carbon via the aromatic amino acid phenylalanine to coumaric acid through phenylalanine ammonia lyase, trans-cinnamate 4-monooxygenase and subsequently to naringenin through the 4-coumaric acid-CoA ligase and chalcone synthase reactions (Figure 1). Deregulation of aromatic amino acid synthesis in $S$. cerevisiae by eliminating feed-back inhibition of DAHP synthase not only increases intracellular phenylalanine levels, but also the intracellular concentration of tyrosine [40]. Since S. cerevisiae cannot interconvert tyrosine and phenylalanine, this increased intracellular availability of tyrosine could not be exploited for naringenin production. In other organisms, deamination of tyrosine by tyrosine ammonia lyase does provide an alternative route to coumaric acid. This has previously been shown to increase naringenin production by $E$ coli when fed with either glucose or tyrosine $[18,20,47]$. To investigate the added benefit of the direct conversion of tyrosine into coumaric acid in S. cerevisiae IMX197, a cotal1 gene from Rhodobacter capsulatus was expressed. This $R$. capsulatus gene was chosen based on its known high catalytic efficiency for tyrosine [48]. Integration of this yeast codon-optimized cotal1 gene resulted in increased naringenin production

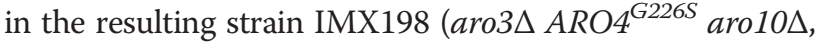

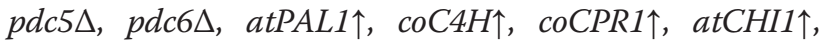

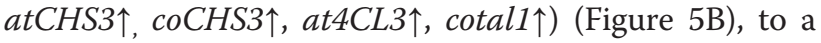
titer of $200 \mu \mathrm{M}$ in shake-flask cultures. Additionally, the phloretic acid concentrations in this strain again increased compared to the parental strain IMX197 $(623,9 \pm 11,4 \mu \mathrm{M}$ and $396,1 \pm 6,9$ respectively), while the coumaric acid concentrations in cultures of the two strains remained the same.

\section{Naringenin production in controlled aerobic batch cultures}

To further characterize strain IMX198 (aro3 $A R O 4^{G 226 S}$ aro $10 \Delta, p d c 5 \Delta, p d c 6 \Delta, \operatorname{atPAL} 1 \uparrow, \quad c o C 4 H \uparrow, \quad c o C P R 1 \uparrow$,

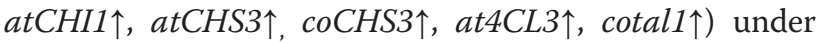
controlled conditions, this strain was cultured in a $2 \mathrm{~L}$ batch bioreactor with $20 \mathrm{~g} \cdot \mathrm{l}^{-1}$ glucose at $\mathrm{pH} 5.0$ (Figure 6A, B). When S. cerevisiae is grown aerobically in 

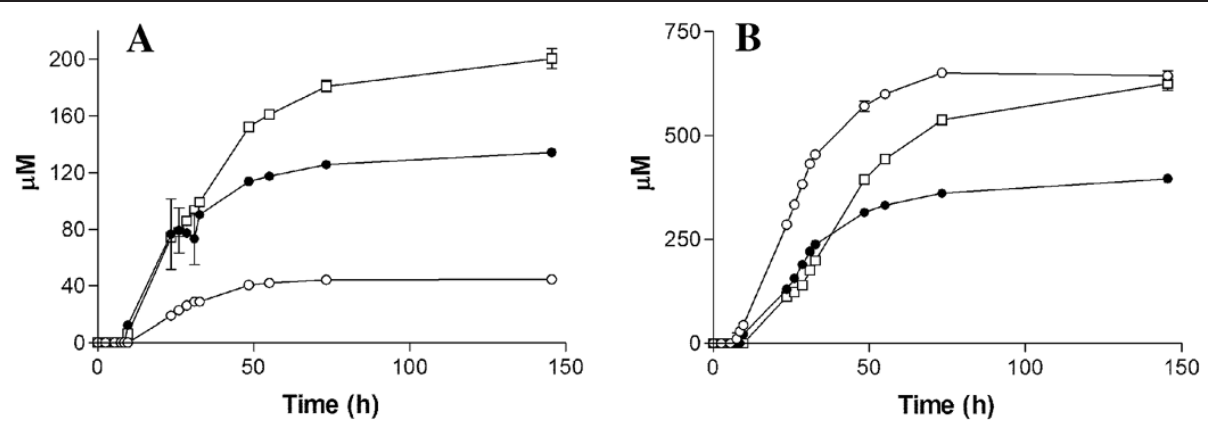

Figure $\mathbf{5}$ Stepwise increase in naringenin formation by $\mathbf{S}$ cerevisiae. Formation of $\mathbf{A})$ naringenin and $\mathbf{B})$ phloretic acid in the engineered

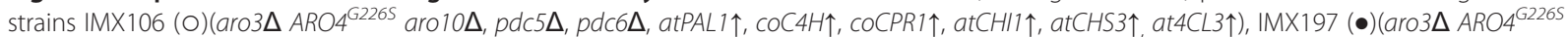

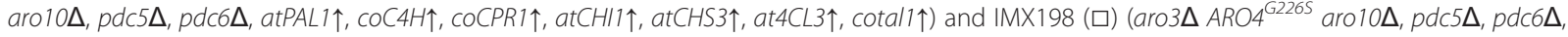

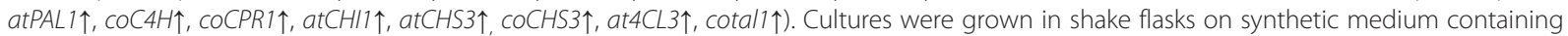
$20 \mathrm{~g}^{. l^{-1}}$ glucose. All cultures were performed in duplicate. Error bar denotes deviation of the mean.

batch cultures on glucose, alcoholic fermentation is the predominant mode of glucose metabolism [49,50] and is characterized by a diauxic growth profile. During the glucose consumption phase the specific growth rate of IMX198 was $0.2 \mathrm{~h}^{-1}$, which is approximately $50 \%$ of the specific growth rate of the reference strain $S$. cerevisiae CEN.PK113-7D under the same conditions [51]. Besides the expected formation of ethanol, a specific naringenin production rate of $12.545 \pm 0.333 \mu \mathrm{molg}^{-1} \mathrm{CDwh}^{-1}$ was obtained. After complete consumption of glucose, a naringenin titer $148.06 \pm 5.67 \mu \mathrm{M}$ at a naringenin yield on glucose of $0.002 \pm 0.000\left(\mathrm{~g} \cdot \mathrm{g}^{-1}\right)$ was obtained. When all the glucose was consumed, ethanol, acetate and glycerol that were produced during the first phase were subsequently consumed (Figure 6A). During this reconsumption phase, naringenin titers increased to $414.63 \pm 1.60 \mu \mathrm{M}$, indicating that most naringenin is produced during this second phase (Figure 6B). However, it must be taken into account that during this reconsumption phase, naringenin production is also facilitated by the presence of available coumarate that was previously formed during the glucose consumption phase and also by the higher amount of biomass, compared to the glucose phase. When only calculating the product yield over the total glucose and ethanol consumption phase, a yield of $0.006 \pm 0.000\left(\mathrm{~g} \cdot \mathrm{g}^{-1}\right)$ was obtained, which is approximately triple of what is obtained during solely the glucose consumption phase.

In summary, the naringenin production of IMX198 in a well aerated and $\mathrm{pH}$ controlled batch bioreactor cultivation required only 38 hours and yielded more than twice the naringenin titer that was achieved in equivalent shake flasks cultivations (200 vs. $415 \mu \mathrm{M})$.

\section{Discussion}

The present study, for the first time, demonstrates de novo production of the key flavonoid intermediate naringenin, from glucose, by an engineered $S$. cerevisiae strain. Combined expression of the product pathway, codon optimization, improvement of precursor supply and reduction of byproduct formation led to concentrations of over $400 \mu \mathrm{M}$ naringenin in aerobic, glucose-grown batch cultures. These concentrations are over 4-fold higher than
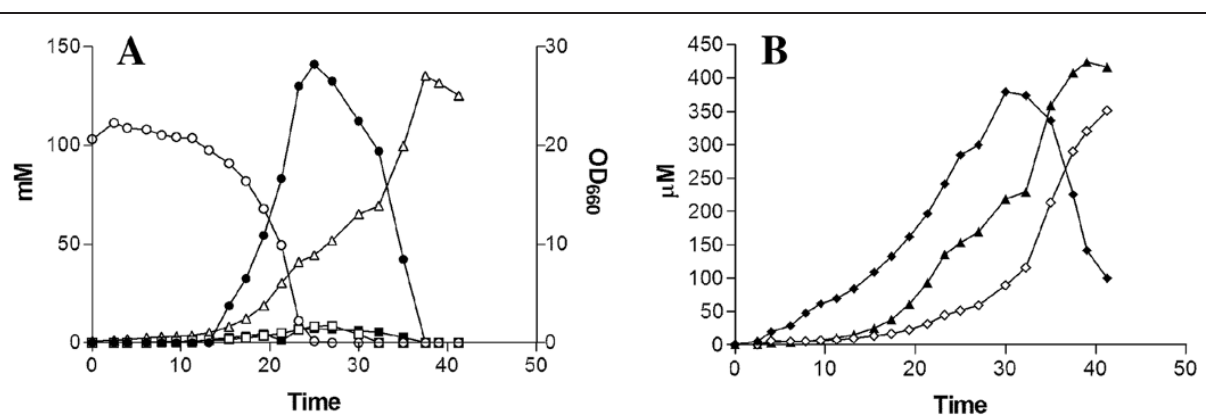

Figure 6 Product formation of the naringenin-producing strain S. cerevisiae IMX198 in bioreactors. Growth and extracellular metabolite formation were studied in aerobic and $\mathrm{pH}$ controlled ( $\mathrm{pH}$ 5.0) batch cultures of IMX198 on glucose. The results shown are from a single representative experiment. A) Concentrations of glucose $(0)$, ethanol $(\bullet)$, acetate $(\square)$, glycerol $(\mathbf{\bullet})$ and optical density $\left(\mathrm{OD}_{660}\right)(\Delta)$. B) Concentrations of naringenin $(\mathbf{\Delta})$, coumaric acid $(\bullet)$ and phloretic acid $(\diamond)$. 
reported in a previous study on de novo biosynthesis of naringenin by an engineered E. coli strain [18].

In previous studies on microbial biotransformation of aromatic precursors to naringenin, the core biosynthetic pathway for naringenin synthesis (phenylalanine and/or tyrosine ammonia lyase, trans-cinnamate 4-monooxygenase, P450 cytochrome reductase, 4-coumaric acid-CoA ligase, chalcone synthase) was, in most cases, reconstituted by co-expressing genes from different plants and/or bacteria $[17-19,27,28]$. Only one of those studies used naringenin biosynthetic genes originating from a single donor organism (A. thaliana), which resulted in the first demonstration of de novo naringenin biosynthesis in E. coli [20]. In line with this observation, co-expression of a set of biosynthetic genes from $A$. thaliana, that were selected based on correlation of in planta expression profiles, was sufficient for low-level de novo production of naringenin in S. cerevisiae (Figure 3). The observations that heterologous co-expression of genes originating from single plant species is beneficial for naringenin production, support the hypothesis that maintaining donor specific protein-protein interactions can improve pathway kinetics and specificity [52]. Besides using genes from a single plant species, also the recently developed synthetic protein scaffolds may be used to explore the impact of the physical association of pathway enzymes [53-55]. The potential of this approach is illustrated by the recent demonstration that protein scaffolding in yeast led to a five-fold increase of the titer of the stilbenoid resveratrol [55]. The optimized supply of precursors and decreased production of aromatic byproducts make the yeast strains developed in this study an interesting models to explore the impact of pathway topology on flavonoid production in a heterologous host.

The improvement of naringenin production in this study followed a typical metabolic engineering approach consisting of repeated cycles of design, construction, and analysis [56]. After introduction of the pathway-encoding genes and observation of low levels of naringenin, alleviation of feedback inhibition of aromatic amino acid biosynthesis by phenylalanine and tyrosine further improved naringenin production. As seen previously [57]. removal of feedback inhibition also resulted in an overflow of phenylalanine into the Ehrlich pathway [40] and, consequently, production of phenylethanol as a major byproduct. Restricting the activity of the Ehrlich pathway by deletion of three decarboxylase-encoding genes strongly reduced formation of phenylethanol and had a strong positive impact on naringenin production (Figure 3). Precursor supply was further improved by expression of a tyrosine ammonia lyase, which introduced a second route towards coumarate besides phenylalanine ammonia lyase. The subsequent introduction of two additional copies of the A. thaliana CHS3 gene further increased the flux from coumaric acid to naringenin (Figure 5B). This observation may be attributed to the catalytic properties of CHS3. This enzyme combines 4 substrates (coumaroyl $\mathrm{CoA}$ and three copies of malonyl $\mathrm{CoA}$ ) to synthesise naringenin, and it is well known to exhibit a very low catalytic activity. Although originating from a different plant, the catalytic constant kcat of the chalcone synthase CHS3 from alfalfa is $2 \mathrm{~min}^{-1}$, [58], which is roughly 25 -fold lower than the kcat of the protein preceding the chalcone synthase in the metabolic pathway, the coumaroyl-CoA ligase (4CL3) from A.thaliana which has a kcat of $50 \mathrm{~min}^{-1}$ [23].

In the naringenin-producing $S$. cerevisiae strains, the by-product phloretic acid was produced in concentrations similar to those achieved for naringenin. Phloretic acid production was only produced in cultures that both accumulated high concentrations of coumaric acid and expressed A. thaliana 4CL3. Phloretic acid has previously been detected in engineered $S$. cerevisiae, but the mechanism of its formation remains unknown [59]. Even though it was observed that increasing the flux to naringenin by increasing the copy number of the A. thaliana CHS3 gene, further analysis of the mechanism of phloretic acid production by these engineered S. cerevisiae, e.g. via systematic gene deletion studies, provides a good opportunity to further improve naringenin production. Also improvement of the provision of malonyl-CoA, a key precursor for both naringenin production as well as for lipid production, might further improve naringenin production. It has previously been shown that overexpression of acetyl-CoA carboxylase, which carboxylates acetyl-CoA to malonyl-CoA, leads to increased production of fatty acids in the yeast Hansenula polymorpha [60] and of biodiesel or 6-methylsalicylic acid production in S. cerevisiae [61,62]. Moreover, malonyl-CoA synthase in E. coli combined with malonate supplementation, improved biotransformation of coumaric acid into flavonoids [63]. Increasing the availability of malonyl-CoA therefore provides an interesting target for further research.

Demonstration of de novo production of naringenin in S. cerevisiae represents an important step towards commercial production of plant-derived flavonoids from glucose. Even though commercial production of naringenin for direct consumer applications will require substantial further improvement of product yields and titers. Furthermore, this engineered naringenin-producing yeast strain provides an attractive platform for expression of plant-derived pathways that convert naringenin into other flavonoids, either by reconstruction of individual plant pathways or by combinatorial approaches based on the powerful yeast-based methods for in vivo recombination $[29,64]$. Availability of a robust yeast platform for such studies paves the way for identification, characterization and eventual industrialization of many 
plant-derived flavonoids with pharma- and nutraceutical properties.

\section{Conclusions}

Here we provide the first report on the production of the flavonoid naringenin from glucose as sole carbon source using the yeast $S$. cerevisiae, and the optimization of the strain to reach a naringenin titer of over $400 \mu \mathrm{M}$. Several obstacles were overcome when expressing a foreign pathway in S. cerevisiae, which include the choice of enzymes, the expression systems the optimization of flux and the inhibition of competing pathways. This study successfully describes the reduction of the phenyl ethanol side product formation. All were done to increase the final titer of flavonoid production.

This strain may be used as an ideal platform for production of a wide variety of flavonoids originating from naringenin, thereby facilitating the production, characterization and possible implementation of such compounds as pharmaceutical and neutraceutical.

\section{Methods}

\section{Strains and maintenance}

All strains used in this study (Table 2) are derived from the $S$. cerevisiae CEN.PK strain family background $[65,66]$. Stock cultures were grown at $30^{\circ} \mathrm{C}$ in $500 \mathrm{ml}$ shake flask cultures containing $100 \mathrm{ml}$ synthetic medium (according to [67]) with $20 \mathrm{g.l} \mathrm{l}^{-1}$ glucose and appropriate growth factors to supplement the specific auxotrophic requirements of the strains [68]. After overnight growth, a final concentration of $20 \%$ glycerol was added and $1 \mathrm{ml}$ aliquots were stored at $-80^{\circ} \mathrm{C}$.

\section{Introduction of chromosomal gene alteration}

Plasmids and oligonucleotide primers used in this study are listed in Tables 2 and 3, respectively. The geneticin (G418) resistance cassette (KanMX4) was amplified by using the pUG6 vector as the template [70]. The KanMX4 PCR product was transformed to the appropriate host (Table 2) using the lithium acetate method [76]. Synthetic medium agar plates containing $2 \%$ glucose and $200 \mathrm{mg} \cdot \mathrm{l}^{-1}$ G418 (Sigma-Aldrich, Zwijdrecht, The Netherlands) and appropriate growth factors to supplement the auxotrophic requirements of the strains, were used to select for the presence of the KanMX4 gene. The KanMX4 marker was removed by the Cre-loxP recombination system using the plasmid pSH47 as described previously [70].

The introduction of a feed-back-insensitive DAHP synthase activity in S.cerevisiae was accomplished in two steps. Firstly, the $A R O 3$ allele was deleted in strain CEN. PK 2.1C using primers ARO3 $\mathrm{KO}$ for and $\mathrm{ARO} 3 \mathrm{KO}$ rev as described above. In this resulting strain, the chromosomal ARO4 allele was replaced by the feed-backinsensitive $A R O 4^{G 226 S}$ allele $[38,39]$. Genomic DNA of strain CEN.PK717.5A was prepared using the genomic DNA isolation kit (Zymo Research, Orange, CA), according to the manufacturer's recommendations. The $A R O 4^{G 226 S}$ allele was then amplified using primers Aro4 for/Aro4 rev, and transformed. Selection was performed by screening for tyrosine tolerance by plating on selective agar plates containing synthetic medium, $2 \%$ glucose and $1 \mathrm{~g} \cdot \mathrm{l}^{-1}$ tyrosine. The resulting strain was named IMK328 (Table 2).

\section{Plasmid construction}

Plasmid pUDE172 was obtained by transformationassociated recombination methods as described previously $[29,30,77]$. The backbone fragment harboring the yeast and bacterial origins of replication and markers was amplified from pAG416GPD-ccdB (Table 2) using primers FK86/87. Genes were optimized for $S$. cerevisiae using the JCat algorithm [78]), based on the A. thaliana gene sequence. The DNA fragments were synthesized (Life Technologies, Bleiswijk, The Netherlands) harboring the yeast codon-optimized genes (codon, promoter, terminator and 2 unique $80 \mathrm{bp}$ flanks that included an EcoRV sites at each end). The codon-optimized plant genes were flanked by different promoter and terminator combinations to prevent plasmid instability due to homologous recombination. Prior to transformation-associated recombination, the synthesized fragments were digested from the cloning vector using EcoRV and gel purified. The pAG416GPD- $c c d B$ backbone fragment and the 3 gene cassettes atPAL1, coC4H and $c o C P R$ were mixed at a ratio of 1:2:2:2 (50ng :100ng; 100ng: 100ng) and transformed to CEN.PK2-1C. Colonies were selected on glucose synthetic medium plates in the absence of uracil and checked by multiplex PCR using the primers FK105 FK112. After plasmid isolation, retransformation to E. coli and subsequent plasmid purification, the structure of the resulting plasmid pUDE172 (Genbank accession number: JX268037) was verified using restriction analysis.

The $A$. thaliana $C H I 1$ gene was amplified using primers FK7/8 from plasmid pUNI.U21762 (Table 2), and then agarose gel purified and digested using SpeI and SalI. The restricted fragment was ligated into an SpeI and SalI linearized pAG305-GPD-ccdB plasmid. The $A$. thaliana 4CL3 gene was amplified using primers FK9/10 from pDZ.4CL3, purified and then ligated into p426TEF (Table 2) using SpeI and SalI. Subsequently, the $\mathrm{P}_{\mathrm{TEF}}$-at $4 C L 3-\mathrm{T}_{\mathrm{TEF}}$ cassette was amplified using primer FK11/12, purified and ligated into a NaeI digested and FastAP (Thermo Scientific, Etten-Leur, The Netherlands) treated pUDI053, yielding pUDI060. The $A$. thaliana CHS3 gene was amplified using primer FK13/14, purified and ligated into p426TPI (Table 2) using SpeI and XhoI yielding pUDE101. The $\mathrm{P}_{\mathrm{TPI}}$-atCHS3- $\mathrm{T}_{\mathrm{ADH}}$ cassette was amplified using primer 
Table 2 Strains and plasmids used in this study

\begin{tabular}{|c|c|c|}
\hline Strain & Genotype & Source \\
\hline CEN.PK2-1C & MATalpha ura3 his3 leu2 trp1 MAL2-8cSUC2 & [69] \\
\hline CEN.PK717.5A & MATa aro3 $\triangle A R O 4^{G 226 S}$ & This study \\
\hline IMU011 & MATalpha ura3 his3 leu2 trp1 MAL2-8cSUC2, pUDE172, PYK2::pUDI065 & This study \\
\hline IMK328 & MATalpha ura3 his3 leu2 trp1 MAL2-8cSUC2 $\triangle$ aro3(46, 1065)::IoxP ARO4 ${ }^{G 2265}$ & This study \\
\hline IMK389 & IMK328 pdc6 $\Delta(-6,-2):: 10 x P$ pdc5 $\Delta(-6,-2):: 10 x P$ & This study \\
\hline IMK393 & IMK389 aro $10 \Delta(-6,-2):: 10 x P$ & This study \\
\hline IMX183 & IMK328 pUDE172, PYK2::pUDI065 & This study \\
\hline IMX185 & IMK389 pUDE172, PYK2::pUDI065 & This study \\
\hline IMX106 & IMK393 pUDE172, PYK2::pUDI065 & This study \\
\hline IMX193 & IMK393 pUDE172, PYK2::pUDI065, TRP1::pUDI069 & This study \\
\hline IMX197 & IMK393 pUDE172, PYK2::pUDI065, pUDE188 & This study \\
\hline IMX198 & IMK393 pUDE172, PYK2::pUDI065, TRP1::pUDI069, pUDE188 & This study \\
\hline \multicolumn{3}{|l|}{ Plasmids } \\
\hline pUG6 & PCR template for loxp-KanMX4-loxp cassette & [70] \\
\hline pSH47 & Centromeric plasmid, URA3, $\mathrm{P}_{\mathrm{GAL} 1}-\mathrm{Cre}-\mathrm{T}_{\mathrm{CYC} 1}$ & [70] \\
\hline pAG416GPD-ccdB & Centromeric plasmid, URA3, $\mathrm{P}_{\mathrm{TDH} 3}-\mathrm{CCd}-\mathrm{T}_{\mathrm{CYC1}}$, Addgene plasmid 14148 & [71] \\
\hline pAG306GPD-ccdB & Integration plasmid, URA3, $\mathrm{P}_{\mathrm{TDH} 3}-\mathrm{ccdb}-\mathrm{T}_{\mathrm{CYC} 1}$, Addgene plasmid 14140 & [71] \\
\hline pAG305GPD-ccdB & Integration plasmid, LEU2, $\mathrm{P}_{\mathrm{TDH} 3}-\mathrm{Ccdb}-\mathrm{T}_{\mathrm{CYC1}}$, Addgene plasmid 14138 & [71] \\
\hline pAG304GPD-ccdB & 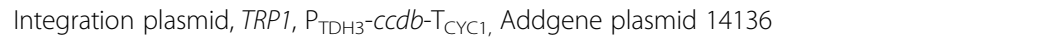 & [71] \\
\hline pAG423GPD-ccdB & $2 \mu \mathrm{m}$ ori, $H_{I S 3}, \mathrm{P}_{\mathrm{TDH} 3}-c \mathrm{Cd} b-\mathrm{T}_{\mathrm{CYC} 1}$, Addgene plasmid 14150 & [71] \\
\hline p426TEF & $2 \mu \mathrm{m}$ ori, $U R A 3, \mathrm{P}_{\mathrm{TEF}}-\mathrm{T}_{\mathrm{TEF}}$ & [72] \\
\hline p426TPI & $2 \mu \mathrm{m}$ ori, $U R A 3 \mathrm{P}_{\mathrm{TPI}}-\mathrm{T}_{\mathrm{ADH}}$ & [73] \\
\hline pUNI.U21762 & Cloning vector, $\mathrm{Ka}$, atCHS3 $\mathrm{CDNA}^{\#}$ & [74] \\
\hline pUNI.U11924 & Cloning vector, $\mathrm{Ka}$, atCHI1 cDNA & [74] \\
\hline pDZ.4CL3 & Cloning vector, Bla, at4CL3 cDNA & [75] \\
\hline pUD168 & pMA cloning vector, Bla, A- $\mathrm{P}_{\mathrm{TDH} 3}-\operatorname{atPAL} 1-\mathrm{T}_{\mathrm{CYC1}}-\mathrm{B}^{*}$ & This study \\
\hline pUD169 & pMA cloning vector, Bla, B-P $\mathrm{PGG}^{-} \mathrm{CO} C P R 1-\mathrm{T}_{\mathrm{PGI}}-\mathrm{C}$ & This study \\
\hline pUD170 & pMA cloning vector, Bla, C-P $\mathrm{P}_{\mathrm{TPI}}{ }^{-} \mathrm{COC} 4 \mathrm{H}-\mathrm{T}_{\mathrm{ADH}^{-}}-\mathrm{D}$ & This study \\
\hline pUD175 & pMA cloning vector, Bla, E-P $\mathrm{PGK}-\mathrm{COCHS3}^{-\mathrm{T}_{\mathrm{PGK}}-\mathrm{F}}$ & This study \\
\hline pUDE185 & $2 \mu \mathrm{m}$ ori, HIS3, $\mathrm{P}_{\mathrm{TDH} 3}-\mathrm{COCHS3}-\mathrm{T}_{\mathrm{CYC} 1}$ & This study \\
\hline pUDE186 & $2 \mu \mathrm{m}$ ori, URA3, $\mathrm{P}_{\mathrm{TEF}}-\mathrm{COCHS3- \textrm {T } _ { \mathrm { TEF } }}$ & This study \\
\hline pUDE188 & 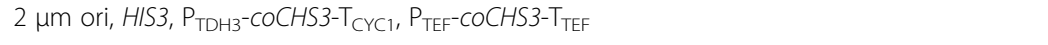 & This study \\
\hline pUDE103 & $2 \mu \mathrm{m}$ ori, URA3, $\mathrm{P}_{\mathrm{TEF}}-\mathrm{at} 4 \mathrm{CL} 3-\mathrm{T}_{\mathrm{TEF}}$ & This study \\
\hline pUDE172 & 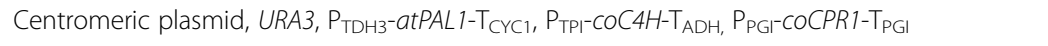 & This study \\
\hline pUDI053 & Integration plasmid, LEU2, $\mathrm{P}_{\mathrm{TDH} 3}-\mathrm{atCH} 11-\mathrm{T}_{\mathrm{CYC} 1}$ & This study \\
\hline pUDI060 & Integration plasmid, LEU2, $\mathrm{P}_{\mathrm{TDH} 3}-\mathrm{atCH} 1-\mathrm{T}_{\mathrm{CYC} 1}, \mathrm{P}_{\mathrm{TEF}}$-at4CL3-T & This study \\
\hline pUDI061 & 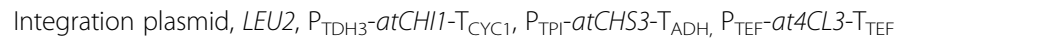 & This study \\
\hline pUDI065 & 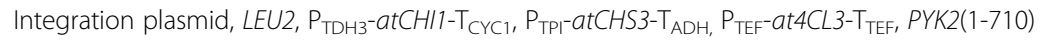 & This study \\
\hline pUDI069 & Integration plasmid, TRP1, $\mathrm{P}_{\mathrm{TDH} 3}{ }^{-C O T A L 1-\mathrm{T}_{\mathrm{CYC1}}}$ & This study \\
\hline
\end{tabular}

* co: codon optimized, \#; at: A. thaliana.

FK15/16, purified and digested by SacI. The resulting fragment was ligated into SacI digested and FastAP treated pUDI060 plasmid, yielding pUDI061. A fragment of the PYK2 gene (1-710bp) was amplified from the CEN.
PK2-1C genome using primer FK29/30, and then purified and digested using $P f o$ I. This fragment was ligated into pUDI061 plasmid that had been digested by PfoI and treated with alkaline phosphatase (FastAP, Thermo 
Table 3 Oligonucleotide primers used in this study

\begin{tabular}{|c|c|}
\hline Name & Sequence $\left(5^{\prime}-3^{\prime}\right)$ \\
\hline \multicolumn{2}{|l|}{$\begin{array}{l}\text { Primers for } \\
\text { knockouts }\end{array}$} \\
\hline ARO3 KO for & $\begin{array}{l}\text { ATGTTCATTAAAAACGATCACGCCGGTGACAGGAAA- } \\
\text { CGCTTGGAAGACTGCAGCTGAAGCTTCGTACG }\end{array}$ \\
\hline ARO3 KO rev & $\begin{array}{l}\text { CTATTIITCAAGGCCTाTCTTCTGTTCTAACACCTTCT- } \\
\text { GCCAATAGCTGCATAGGCCACTAGTGGATCTG }\end{array}$ \\
\hline PDC5 KO for & $\begin{array}{l}\text { CATAATCAATCTCAAAGAGAACAACACAATACAATAA- } \\
\text { CAAGAAGAACAAACAGCTGAAGCTTCGTACGC }\end{array}$ \\
\hline PDC5 KO rev & $\begin{array}{l}\text { AAAGTAAAAAAATACACAAACGTTGAATCATGAGTTT } \\
\text { ATGTTAATTAGCGCATAGGCCACTAGTGGATCTG }\end{array}$ \\
\hline PDC6 KO for & $\begin{array}{l}\text { GGCGGCTGTITGAAGCCATTCTATCTTAATCTTGTGCT- } \\
\text { ATTGCAGTCCTCCAGCTGAAGCTTCGTACGC }\end{array}$ \\
\hline PDC6 KO rev & $\begin{array}{l}\text { GTAAGTITATTTGCAACAATAATTCGTTTGAGTACACT- } \\
\text { ACTAATGGCGCATAGGCCACTAGTGGATCTG }\end{array}$ \\
\hline ARO10 KO for & $\begin{array}{l}\text { GATACTCAAAACAAGTTGACGCGACTTCTGTAAAGTT- } \\
\text { ATTACAAGATAACAAAGAAACTCCCTTAAGCCAGCT- } \\
\text { GAAGCTTCGTACGC }\end{array}$ \\
\hline ARO10 KO rev & $\begin{array}{l}\text { GGGTTITATGTGTTAATGAACAGAAAACGAAC- } \\
\text { AATTGGTAGCAGTGTIITATAATGGGCCCACAAGT- } \\
\text { CATAGGCCACTAGTGGATCTG }\end{array}$ \\
\hline ARO4 for & GACGCATTGTTAGCATTG \\
\hline ARO4 rev & CGAATTGGCAGTGGTAGAG \\
\hline \multicolumn{2}{|l|}{$\begin{array}{l}\text { Primers for } \\
\text { cloning }\end{array}$} \\
\hline FK7 & GCGACTAGTATGTCTTCATCCAACGCC \\
\hline FK8 & GCGGTCGACTCAGTTCTCTTTGGCTAGTT \\
\hline FK9 & GCGACTAGTATGATCACTGCAGCTCTAC \\
\hline FK10 & GCGGTCGACTCAACAAAGCTTAGCTTTGAG \\
\hline FK11 & GAGGCCGGCGCAATTAACCCTCACTAAAG \\
\hline FK12 & TGGACTCCAACGTCAAAG \\
\hline FK13 & GCGACTAGTATGGTGATGGCTGGTGC \\
\hline FK14 & GCGCTCGAGTTAGAGAGGAACGCTGTGC \\
\hline FK15 & CGCGCAATTAACCCTCAC \\
\hline FK16 & GCGGAGCTCCACTATAGGGCGAATTGGG \\
\hline FK29 & GCGTCCCGGAATGCCAGAGTCCAGATTG \\
\hline FK30 & GCGTCCCGGAGATATCTTGCCCTTCAGAACCC \\
\hline FK52 & GCGACTAGTATGACCTTACAATCCCAAAC \\
\hline FK53 & GCGCTCGAGTTAGGCTGGAG \\
\hline FK86 & $\begin{array}{l}\text { ATCATGAACTTGCGCTCAATTCCGCGCAGAAGGCAA- } \\
\text { TGCTATAAGACCCACGTCCACGGATTGCGCCTAA- } \\
\text { GACCGGATAAAGCACCGCATAGGG-TAATAACTG }\end{array}$ \\
\hline FK87 & $\begin{array}{l}\text { ATCGGAAATTCGACCGTGTGCTAGTGCCTATTGATGA- } \\
\text { TCTGGCGGAATGTCTGCCGTGCCATAGCCATGCCTT- } \\
\text { CACATATAGTGTAATACGGTTATCCACAGAATC }\end{array}$ \\
\hline FK169 & GCGACTAGTATGGTTATGGCTGGTGC \\
\hline FK170 & GCGCTCGAGAATTACAATGGAACAGAGTGC \\
\hline FK171 & GCGGAGCTCGCTGGAGCTCATAGCTTC \\
\hline FK172 & GCGGAGCTCGTACCCAGTATAGCGACC \\
\hline
\end{tabular}

Table 3 Oligonucleotide primers used in this study (Continued)

\begin{tabular}{ll}
\hline $\begin{array}{l}\text { Primers for } \\
\text { verification }\end{array}$ & \\
FK105 & TCTICCTGCGTATCCC \\
FK106 & GGCATGTACGGGTACAG \\
FK107 & CGCGTGTACGCATGTAAC \\
FK108 & TCCCGTTAGGAACATTGG \\
FK109 & GCAAATGCCTGCAAATCG \\
FK110 & AACGTGCAGATGGTGATG \\
FK111 & CATTATTGAACAGCGTCCAAG \\
FK112 & AGAACCGTGGATGATGTG \\
\hline
\end{tabular}

Scientific) yielding pUDI065 (Genbank accession number: JX268039). The resulting plasmid was linearized using $\mathrm{NcoI}$ and integrated into the chromosomal PYK2 locus.

The tal1 gene from $R$. capsulatus [48,79], was codon optimized for yeast using JCat [78], and synthesized (GeneScript, Piscataway, NJ). The synthetic cotal1 was amplified using primers FK52/53 and ligated into pAG304- $c c d B$ using SpeI and XhoI resulting in pUDI069 (Genbank accession number: JX268036). Integration of this plasmid into the trp1 locus was preceded by linearization using EcoRV.

A DNA fragment containing the custom-synthesized, yeast codon-optimized CHS3 sequence (Life Technologies, Bleiswijk, The Netherlands) was amplified using primers FK169/170 and ligated into both a pAG325GPD-ccdB and p426TEF (Table 2) using SpeI and XhoI yielding respectively, pUDE185 and 186. Subsequently, the $\mathrm{P}_{\mathrm{TEF}}{ }^{-C O C H S 3-}$ $\mathrm{T}_{\text {TEF }}$ cassette was amplified using primers FK 171/172 and restricted using SacI. This cassette was ligated into a SacI digested and FastAP (Thermo Scientific) treated pUDE185. Plasmids were screened for opposing gene orientation by restriction analysis, yielding pUDE188 (Genbank accession number: JX268038).

\section{Molecular biology procedures}

PCR amplification was performed using Phusion ${ }^{\circledR}$ Hot Start II High Fidelity Polymerase (Thermo Scientific) according to the manufacturer's instructions in a Biometra TGradient Thermocycler (Biometra, Gottingen, Germany). Agarose gel separation was performed using 1\% (w/v) agarose (Sigma-Aldrich, Zwijdrecht, The Netherlands) gel in $1 \times$ TAE ( $40 \mathrm{mM}$ Tris-acetate $\mathrm{pH} 8.0$ and $1 \mathrm{mM}$ EDTA). Isolation of agarose trapped fragments was performed using Zymoclean Gel DNA Recovery kit (Zymo Research, Orange, CA). Restriction endonucleases, DNA ligases and FastAP (Thermo Scientific) were used according to the manufacturer's instructions. Transformation and amplification of plasmids were performed in E. coli 
DH5 $\alpha$ electrocompetent cells (Invitrogen, Carlsbad, CA) according to the manufacturer's instructions. Plasmids were isolated from $E$. coli with the Sigma GenElute Plasmid Miniprep Kit (Sigma-Aldrich). Alternatively, plasmid purification was performed using a Zymoprep ${ }^{\mathrm{TM}}$ Yeast Plasmid Miniprep (Zymo Research). Sequencing of constructs was performed by Baseclear BV (Baseclear, Leiden, The Netherlands).

\section{Cultivation and media}

E. coli was grown at $37^{\circ} \mathrm{C}$ in Luria Broth medium containing the appropriate antibiotic, $100 \mu \mathrm{g} \cdot \mathrm{l}^{-1}$ ampicillin or $50 \mu \mathrm{g} \cdot \mathrm{l}^{-1}$ kanamycin (Sigma-Aldrich, Zwijndrecht, The Netherlands). S. cerevisiae was grown at $30^{\circ} \mathrm{C}$ in medium containing demineralized water, $20 \mathrm{~g} \cdot \mathrm{l}^{-1}$ glucose, $5 \mathrm{~g} \cdot \mathrm{l}^{-1}$

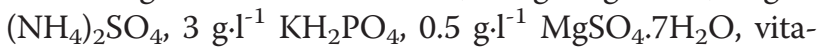
mins and trace elements [67]. The $\mathrm{pH}$ of the medium was set to 6.0 using $\mathrm{KOH}$. Appropriate growth factors to supplement the auxotrophic requirements of the strains were added at $150 \mathrm{mg} \cdot \mathrm{l}^{-1}$ for uracil, $500 \mathrm{mg} \cdot \mathrm{l}^{-1}$ for leucine, $75 \mathrm{mg} \cdot \mathrm{l}^{-1}$ for tryptophan and $125 \mathrm{mg} \cdot \mathrm{l}^{-1}$ for histidine [68]. Unless otherwise stated, cultures were grown in $500 \mathrm{ml}$ shake flasks with $100 \mathrm{ml}$ medium by adding $1 \mathrm{ml}$ frozen stock culture and incubating at $30^{\circ} \mathrm{C}$ in an Innova incubator shaker (New Brunswick Scientific, Edison, NJ) set at $200 \mathrm{rpm}$. Controlled aerobic batch cultures were grown at $30^{\circ} \mathrm{C}$ in 21 bioreactors (Applikon, Schiedam, The Netherlands), using a working volume of 11 . In the bioreactor experiments, the $\left(\mathrm{NH}_{4}\right)_{2} \mathrm{SO}_{4}$ concentration in the synthetic medium was increased to $10 \mathrm{~g} \cdot \mathrm{l}^{-1}$ to avoid nitrogen depletion towards the end of the culture. Emulsion C antifoam at $0.05 \%(\mathrm{w} / \mathrm{v})$ (Sigma-Aldrich, Zwijndrecht, The Netherlands) was added separately after autoclaving. The $\mathrm{pH}$ was maintained at $\mathrm{pH} 5.0$ by automatic addition of either $2 \mathrm{M} \mathrm{KOH}$ or $2 \mathrm{M} \mathrm{H}_{2} \mathrm{SO}_{4}$, the stirrer speed was fixed at $800 \mathrm{rpm}$ and the aeration rate was set at $500 \mathrm{ml} \cdot \mathrm{min}^{-1}$.

\section{Analytical methods}

Optical density was measured at $660 \mathrm{~nm}$ using a Libra S11 spectrophotometer (Biochrom, Cambridge, UK). Biomass dry weights were determined by filtration of $10 \mathrm{ml}$ culture over dry, preweighed $0.45 \mu \mathrm{m}$ nitrocellulose filters (Gelman Laboratory, Ann Arbor, USA). After removal of the medium, the filter was washed twice with demineralized water and dried for 20 min using a microwave set at 350 W. Glucose, ethanol, glycerol and acetate were analyzed using an Aminex HPX-87H ion exchange column (BioRad, Veenendaal, The Netherlands) operated at $60^{\circ} \mathrm{C}$ with $5 \mathrm{mM}$ $\mathrm{H}_{2} \mathrm{SO}_{4}$ as mobile phase at a flow rate of $0.6 \mathrm{ml} \cdot \mathrm{min}^{-1}$. For measurement of phenylpropanoic compounds, culture samples were diluted with an equal volume of $100 \%$ ethanol. After vigorous mixing, cells were spun down at 13000 rpm in a Sorval Heraeus \#3328 rotor for $2 \mathrm{~min}$. The supernatant was analysed using HPLC. For phenylpropanoic compounds, measurements were made using a Waters 2695 separation module and a Waters 996 photodiode array detector. Phloretic acid, coumaric acid, phenyl ethanol, cinnamic acid and naringenin were measured respectively at 275, 309, 214, 277, $289 \mathrm{~nm}$ using an Agilent Zorbax SB-C18 Column (4.6 × 5.0, 3.5 micron) operating at

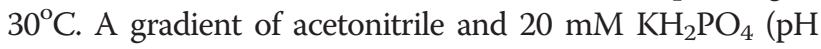
2) with $1 \%$ acetonitrile was used as eluent, at a flow rate of $1 \mathrm{ml} \cdot \mathrm{min}^{-1}$, increasing from 0 to $10 \%$ acetonitrile in $6 \mathrm{~min}$ followed by an increase to $40 \%$ acetonitrile until $23 \mathrm{~min}$. From $23 \mathrm{~min}$ to $27 \mathrm{~min}$, the flow was set to $100 \% \mathrm{KH}_{2} \mathrm{PO}_{4}$. Naringenin, coumaric acid, cinnamic acid, phloretic acid and phenylethanol standards were obtained from Sigma Aldrich (Sigma-Aldrich, Zwijndrecht, The Netherlands).

For analysis of carbon dioxide production in bioreactor cultures, the off-gas was first cooled in a condenser $\left(2^{\circ} \mathrm{C}\right)$ and dried with a Perma Pure Dryer (Permapure, Toms River, NJ). $\mathrm{CO}_{2}$ concentrations in the off-gas were then measured with a NGA 2000 Rosemount gas analyzer (Rosemount Analytical, Orrville,OH).

Identification of phenylpropanoid intermediates and naringenin was performed using liquid chromatography coupled to both photodiode-array detection and accurate mass quadrupole time-of-flight mass spectrometry (LC-PDA-QTOF MS) was performed using a Waters Alliance 2795 HPLC connected to a Waters 2996 PDA detector and subsequently a QTOF Ultima V4.00.00 mass spectrometer (Waters, MS technologies, UK) operating in negative ionization mode, an analytical column (Luna $3 \mu \mathrm{C} 18 / 2$ 100A; $2.0 \times 150$ $\mathrm{mm})$ attached to a C18 pre-column $(2.0 \times 4 \mathrm{~mm}$; AJO-4286; both Phenomenex, USA). Eluents A (ultrapure water:formic acid (1000:1, v/v) ) and B (acetonitrile : formic acid (1000: 1, v/v) ) were used at 0.19 ml.min. The gradient started at 5\% B and increased linearly to $35 \% \mathrm{~B}$ in $45 \mathrm{~min}$, after which the column was washed and equilibrated for $15 \mathrm{~min}$ before the next injection. The injection volume was 5 $\mu$ l. Leucine enkephalin $([\mathrm{M}-\mathrm{H}]-=554.2620)$ was used as a lock mass for on-line accurate mass correction [80]. Data were recorded using MassLynx 4.0 software (Waters).

\section{Co-expression correlation analysis of naringenin biosynthetic genes in $A$. thaliana}

Expression correlation analysis was performed using the BAR Expression Angler [35]. Each candidate gene listed in Table 1 was used as "bait", and expression was correlated over a set of 392 micro-array experiments generated using the ATH1 Affymetrix Whole Genome GeneChip, from the Nottingham Arabidopsis Stock Centre's microarray database [34]. Correlations between expression levels of genes 
from Table 1 were recorded when the Pearson correlation coefficient was above 0.6.

\section{Competing interests}

The authors declare that they have no competing interests.

\section{Authors' contributions}

FK, AJAM, JTP and JB designed the study. FK engineered the plasmids, strains and all genetic alterations and performed batch fermentations. FK and BC performed all shake flask culture experiments. JB and AvdH performed the transcriptional correlation analysis. FK performed all analytical quantification with the input of JB. FK, JB, AJAM, JTP, RDH, DB and J-MD drafted the manuscript. All authors have critiqued and approved the final manuscript.

\section{Acknowledgements}

We thank Marinka Almering, Erik de Hulster, Bart Oud and Victor Guadalupe Medina for their technical assistance. The research group of JTP is part of the Kluyver Centre for Genomics of Industrial Fermentation (http://www. kluyvercentre.nl/pro1/general/home.asp/); the research group of RDH is part of the Centre for BioSYstems Genomics, both of which are supported by The Netherlands Genomics Initiative (http://www.genomics.nl/). FK, JTP and J-MD. were also supported by the "Platform Green Synthetic Biology" programme (http://www.pgsb.nl/) funded by NGI. FK, J-MD, AJAM were also financially supported by NGl through the Horizon breakthrough programme (project 93519011). JB, AH and RDH acknowledge support by the EU $7^{\text {th }}$ Framework ATHENA project (FP7-KBBE-2009-3-245121-ATHENA). This research was also supported by BIOFLAVOUR, COST Action FA0907 (www.bioflavour.insatoulouse.fr).

\section{Author details}

'Department of Biotechnology, Delft University of Technology, Julianalaan 67, 2628 BC Delft, the Netherlands. ${ }^{2}$ Platform for Green Synthetic Biology, P.O. Box 5057, 2600 GA Delft, The Netherlands. ${ }^{3}$ Kluyver Centre for Genomics of Industrial Fermentation, P.O. Box 5057, 2600 GA Delft, The Netherlands. ${ }^{4}$ Plant Research International (PRI), P.O. Box 16, 6700 AA Wageningen, The Netherlands. ${ }^{5}$ Centre for Biosystems Genomics, PO Box 98, 6700 AB Wageningen, The Netherlands.

\section{Received: 4 September 2012 Accepted: 15 November 2012} Published: 8 December 2012

\section{References}

1. Xu P, Ranganathan S, Fowler ZL, Maranas CD, Koffas MA: Genome-scale metabolic network modeling results in minimal interventions that cooperatively force carbon flux towards malonyl-CoA. Metab Eng 2011, 13:578-587.

2. Facchini PJ, Bohlmann J, Covello PS, De Luca V, Mahadevan R, Page JE, Ro DK, Sensen CW, Storms R, Martin VJ: Synthetic biosystems for the production of high-value plant metabolites. Trends Biotechnol 2012, 30:127-131.

3. Xiao ZP, Peng ZY, Peng MJ, Yan WB, Ouyang YZ, Zhu HL: Flavonoids Health Benefits and Their Molecular Mechanism. Mini-Rev Med Chem 2011, 11:169-177.

4. Wedick NM, Pan A, Cassidy A, Rimm EB, Sampson L, Rosner B, Willett W, Hu FB, Sun Q, van Dam RM: Dietary flavonoid intakes and risk of type 2 diabetes in US men and women. Am J Clin Nutr 2012, 95:925-933.

5. Knekt $P$, Kumpulainen J, Jarvinen $R$, Rissanen $H$, Heliovaara $M$, Reunanen $A$, Hakulinen T, Aromaa A: Flavonoid intake and risk of chronic diseases. Am J Clin Nutr 2002, 76:560-568.

6. Wang B, Zhang X: Inhibitory effects of Broccolini leaf flavonoids on human cancer cells. Scanning 2012, 34:1-5.

7. McCullough ML, Peterson JJ, Patel R, Jacques PF, Shah R, Dwyer JT: Flavonoid intake and cardiovascular disease mortality in a prospective cohort of US adults. Am J Clin Nutr 2012, 95:454-464.

8. Martin C, Butelli E, Petroni K, Tonelli C: How can research on plants contribute to promoting human health? Plant Cell 2011, 23:1685-1699.

9. Zava DT, Duwe G: Estrogenic and antiproliferative properties of genistein and other flavonoids in human breast cancer cells in vitro. Nutr Cancer 1997, 27:31-40.

10. Greenwald P: Clinical trials in cancer prevention: current results and perspectives for the future. J Nutr 2004, 134:3507S-3512S.
11. Hou DX, Fujii M, Terahara N, Yoshimoto M: Molecular mechanisms behind the chemopreventive effects of anthocyanidins. J Biomed Biotechnol 2004, 2004:321-325.

12. Allister EM, Borradaile NM, Edwards JY, Huff MW: Inhibition of microsomal triglyceride transfer protein expression and apolipoprotein B100 secretion by the citrus flavonoid naringenin and by insulin involves activation of the mitogen-activated protein kinase pathway in hepatocytes. Diabetes 2005, 54:1676-1683.

13. Fowler $\mathrm{ZL}$, Koffas MA: Biosynthesis and biotechnological production of flavanones: current state and perspectives. Appl Microbiol Biotechnol 2009, 83:799-808.

14. Wang $Y$, Chen $S, Y u$ O: Metabolic engineering of flavonoids in plants and microorganisms. Appl Microbiol Biotechnol 2011, 91:949-956.

15. Nijveldt RJ, van Nood E, van Hoorn DE, Boelens PG, van Norren K, van Leeuwen PA: Flavonoids: a review of probable mechanisms of action and potential applications. Am J Clin Nutr 2001, 74:418-425.

16. Limem I, Guedonc E, Hehn A, Bourgaud F, Ghedira LC, Engasser JM, Ghoul M: Production of phenylpropanoid compounds by recombinant microorganisms expressing plant-specific biosynthesis genes. Process Biochem 2008, 43:463-479.

17. Leonard E, Lim KH, Saw PN, Koffas MA: Engineering central metabolic pathways for high-level flavonoid production in Escherichia coli. Appl Environ Microbio/ 2007, 73:3877-3886.

18. Santos CNS, Koffas M, Stephanopoulos G: Optimization of a heterologous pathway for the production of flavonoids from glucose. Metab Eng 2011 13:392-400.

19. Trantas E, Panopoulos N, Ververidis F: Metabolic engineering of the complete pathway leading to heterologous biosynthesis of various flavonoids and stilbenoids in Saccharomyces cerevisiae. Metab Eng 2009, 11:355-366.

20. Watts KT, Lee PC, Schmidt-Dannert C: Exploring recombinant flavonoid biosynthesis in metabolically engineered Escherichia coli. Chem Biochem 2004, 5:500-507.

21. Koopmann E, Hahlbrock K: Differentially regulated NADPH: cytochrome P450 oxidoreductases in parsley. Proc Natl Acad Sci USA 1997, 94:14954-14959.

22. Winkel-Shirley B: Flavonoid biosynthesis. A colorful model for genetics, biochemistry, cell biology, and biotechnology. Plant Physiol 2001, 126:485-493.

23. Costa MA, Bedgar DL, Moinuddin SG, Kim KW, Cardenas CL, Cochrane FC, Shockey JM, Helms GL, Amakura Y, Takahashi H, et al: Characterization in vitro and in vivo of the putative multigene 4-coumarate:CoA ligase network in Arabidopsis: syringyl lignin and sinapate/sinapyl alcohol derivative formation. Phytochem 2005, 66:2072-2091.

24. Burbulis IE, Winkel-Shirley B: Interactions among enzymes of the Arabidopsis flavonoid biosynthetic pathway. Proc Natl Acad Sci USA 1999 96:12929-12934.

25. Winkel BSJ: Metabolic channeling in plants. Annu Rev Plant Biol 2004, 55:85-107.

26. Yu O, Shi J, Hession AO, Maxwell CA, McGonigle B, Odell JT: Metabolic engineering to increase isoflavone biosynthesis in soybean seed. Phytochem 2003, 63:753-763.

27. Jiang $H$, Wood KV, Morgan JA: Metabolic engineering of the phenylpropanoid pathway in Saccharomyces cerevisiae. Appl Environ Microbiol 2005, 71:2962-2969.

28. Yan Y, Chemler J, Huang L, Martens S, Koffas MA: Metabolic engineering of anthocyanin biosynthesis in Escherichia coli. Appl Environ Microbiol 2005, 71:3617-3623.

29. Gibson DG, Benders GA, Andrews-Pfannkoch C, Denisova EA, Baden-Tillson $H$, Zaveri J, Stockwell TB, Brownley A, Thomas DW, Algire MA, et al: Complete chemical synthesis, assembly, and cloning of a Mycoplasma genitalium genome. Science 2008, 319:1215-1220.

30. Shao Z, Zhao H: DNA assembler, an in vivo genetic method for rapid construction of biochemical pathways. Nucleic Acids Res 2009, 37:e16.

31. Jiang $H$, Morgan JA: Optimization of an in vivo plant P450 monooxygenase system in Saccharomyces cerevisiae. Biotechnol Bioeng 2004, 85:130-137.

32. Zhang $\mathrm{YH}$ : Substrate channeling and enzyme complexes for biotechnological applications. Biotechnol Adv 2011, 29:715-725.

33. Raes J, Rohde A, Christensen JH, Van de Peer Y, Boerjan W: Genome-wide characterization of the lignification toolbox in Arabidopsis. Plant Physiol 2003, 133:1051-1071. 
34. Craigon DJ, James N, Okyere J, Higgins J, Jotham J, May S: NASCArrays: a repository for microarray data generated by NASC's transcriptomics service. Nucleic Acids Res 2004, 32:D575-D577.

35. Toufighi K, Brady SM, Austin R, Ly E, Provart NJ: The botany array resource: e-northerns, expression angling, and promoter analyses. Plant J 2005, 43:153-163.

36. Saito K, Hirai MY, Yonekura-Sakakibara K: Decoding genes with coexpression networks and metabolomics - 'majority report by precogs'. Trends Plant Sci 2008, 13:36-43.

37. Ehlting J, Buttner D, Wang Q, Douglas CJ, Somssich IE, Kombrink E: Three 4-coumarate:coenzyme A ligases in Arabidopsis thaliana represent two evolutionarily divergent classes in angiosperms. Plant J 1999, 19:9-20.

38. Schnappauf G, Hartmann M, Kunzler M, Braus GH: The two 3-deoxy-Darabino-heptulosonate-7-phosphate synthase isoenzymes from Saccharomyces cerevisiae show different kinetic modes of inhibition. Arch Microbiol 1998, 169:517-524.

39. Hartmann M, Schneider TR, Pfeil A, Heinrich G, Lipscomb WN, Braus GH: Evolution of feedback-inhibited beta/alpha barrel isoenzymes by gene duplication and a single mutation. Proc Natl Acad Sci USA 2003, 100:862-867.

40. Luttik MA, Vuralhan Z, Suir E, Braus GH, Pronk JT, Daran JM: Alleviation of feedback inhibition in Saccharomyces cerevisiae aromatic amino acid biosynthesis: quantification of metabolic impact. Metab Eng 2008, 10:141-153

41. Vuralhan Z, Luttik MA, Tai SL, Boer VM, Morais MA, Schipper D, Almering MJ, Kotter P, Dickinson JR, Daran JM, Pronk JT: Physiological characterization of the ARO10-dependent, broad-substrate-specificity 2-oxo acid decarboxylase activity of Saccharomyces cerevisiae. Appl Environ Microbiol 2005, 71:3276-3284.

42. Vuralhan Z, Morais MA, Tai SL, Piper MD, Pronk JT: Identification and characterization of phenylpyruvate decarboxylase genes in Saccharomyces cerevisiae. Appl Environ Microbiol 2003, 69:4534-4541.

43. Hazelwood LA, Daran JM, van Maris AJ, Pronk JT, Dickinson JR: The Ehrlich pathway for fusel alcohol production: a century of research on Saccharomyces cerevisiae metabolism. Appl Environ Microbiol 2008, 74:2259-2266

44. Romagnoli G, Luttik MA, Kotter P, Pronk JT, Daran JM: Substrate specificity of thiamine-pyrophosphate-dependent 2-oxo-acid decarboxylases in Saccharomyces cerevisiae. Appl Environ Microbiol, 78:7538-7548.

45. Flikweert MT, de Swaaf M, van Dijken JP, Pronk JT: Growth requirements of pyruvate-decarboxylase-negative Saccharomyces cerevisiae. FEMS Microbiol Lett 1999, 174:73-79.

46. Zuurbier KWM, Fung SY, Scheffer JJC, Verpoorte R: Assay of chalcon synthase activity by high-performance liquid-chromatography. Phytochem 1993, 34:1225-1229.

47. Hwang El, Kaneko M, Ohnishi Y, Horinouchi S: Production of plant-specific flavanones by Escherichia coli containing an artificial gene cluster. Appl Environ Microbiol 2003, 69:2699-2706.

48. Kyndt JA, Meyer TE, Cusanovich MA, Van Beeumen JJ: Characterization of a bacterial tyrosine ammonia lyase, a biosynthetic enzyme for the photoactive yellow protein. FEBS Lett 2002, 512:240-244.

49. De Deken RH: The Crabtree effect: a regulatory system in yeast. J Gen Microbiol 1966, 44:149-156.

50. Van Hoek P, Van Dijken JP, Pronk JT: Effect of specific growth rate on fermentative capacity of baker's yeast. Appl Environ Microbiol 1998, 64:4226-4233.

51. van Maris AJA, Bakker BM, Brandt M, Boorsma A, de Mattos MJT, Grivell LA, Pronk JT, Blom J: Modulating the distribution of fluxes among respiration and fermentation by overexpression of HAP4 in Saccharomyces cerevisiae. FEMS Yeast Research 2001, 1:139-149.

52. Winkel-Shirley B: Evidence for enzyme complexes in the phenylpropanoid and flavonoid pathways. Physiol Plant 1999, 107:142-149.

53. Dueber JE, Wu GC, Malmirchegini GR, Moon TS, Petzold CJ, Ullal AV, Prather $\mathrm{KL}$, Keasling JD: Synthetic protein scaffolds provide modular control over metabolic flux. Nat Biotechnol 2009, 27:753-759.

54. Moon TS, Dueber JE, Shiue E, Prather KLJ: Use of modular, synthetic scaffolds for improved production of glucaric acid in engineered E. coli. Metab Eng 2010, 12:298-305.

55. Wang Y, Yu O: Synthetic scaffolds increased resveratrol biosynthesis in engineered yeast cells. J Biotechnol 2011, 157:258-260.
56. Kim IK, Roldao A, Siewers $V$, Nielsen J: A systems-level approach for metabolic engineering of yeast cell factories. FEMS Yeast Res 2012, 12:228-248.

57. Santos CNS: Combinatorial search strategies for the metabolic engineering of microorganisms. Cambridge, MA: Massachusetts Institute of Technology, PhD thesis; 2010.

58. Jez JM, Ferrer JL, Bowman ME, Dixon RA, Noel JP: Dissection of malonylcoenzyme A decarboxylation from polyketide formation in the reaction mechanism of a plant polyketide synthase. Biochemistry 2000, 39:890-902.

59. Beekwilder J, Wolswinkel R, Jonker $\mathrm{H}$, Hall R, de Vos CH, Bovy A: Production of resveratrol in recombinant microorganisms. Appl Environ Microbiol 2006, 72:5670-5672.

60. Ruenwai R, Cheevadhanarak S, Laoteng K: Overexpression of acetyl-CoA carboxylase gene of Mucor rouxii enhanced fatty acid content in Hansenula polymorpha. Mol Biotechnol 2009, 42:327-332

61. Shi S, Valle-Rodriguez JO, Khoomrung S, Siewers V, Nielsen J: Functional expression and characterization of five wax ester synthases in Saccharomyces cerevisiae and their utility for biodiesel production. Biotechnol Biofuels 2012, 5:7.

62. Wattanachaisaereekul S, Lantz AE, Nielsen ML, Nielsen J: Production of the polyketide 6-MSA in yeast engineered for increased malonyl-CoA supply. Metab Eng 2008, 10:246-254

63. Leonard E, Yan Y, Fowler ZL, Li Z, Lim CG, Lim KH, Koffas MA: Strain improvement of recombinant Escherichia coli for efficient production of plant flavonoids. Mol Pharm 2008, 5:257-265.

64. Naesby M, Nielsen SV, Nielsen CA, Green T, Tange TO, Simon E, Knechtle P, Hansson A, Schwab MS, Titiz O, et al: Yeast artificial chromosomes employed for random assembly of biosynthetic pathways and production of diverse compounds in Saccharomyces cerevisiae. Microb Cell Fact 2009, 8:45.

65. van Dijken JP, Bauer J, Brambilla L, Duboc P, Francois JM, Gancedo C, Giuseppin ML, Heijnen JJ, Hoare M, Lange HC, et al: An interlaboratory comparison of physiological and genetic properties of four Saccharomyces cerevisiae strains. Enzyme Microb Technol 2000, 26:706-714.

66. Nijkamp JF, van den Broek M, Datema E, de Kok S, Bosman L, Luttik MA, Daran-Lapujade P, Vongsangnak W, Nielsen J, Heijne WH, et al: De novo sequencing, assembly and analysis of the genome of the laboratory strain Saccharomyces cerevisiae CEN.PK113-7D, a model for modern industrial biotechnology. Microb Cell Fact 2012, 11:36.

67. Verduyn C, Postma E, Scheffers WA, Vandijken JP: Physiology of Saccharomyces cerevisiae in Anaerobic Glucose-Limited Chemostat Cultures. J Gen Microbiol 1990, 136:395-403.

68. Pronk JT: Auxotrophic yeast strains in fundamental and applied research. Appl Environ Microbiol 2002, 68:2095-2100.

69. Entian KD, Kotter P: 25 Yeast genetic strain and plasmid collections. Method Microbiol 2007, 36:629-666

70. Gueldener U, Heinisch J, Koehler GJ, Voss D, Hegemann JH: A second set of loxP marker cassettes for Cre-mediated multiple gene knockouts in budding yeast. Nucleic Acids Res 2002, 30:e23.

71. Alberti $S$, Gitler $A D$, Lindquist S: A suite of Gateway ${ }^{(R)}$ cloning vectors for high-throughput genetic analysis in Saccharomyces cerevisiae. Yeast 2007, 24:913-919.

72. Mumberg D, Muller R, Funk M: Yeast Vectors for the Controlled Expression of Heterologous Proteins in Different Genetic Backgrounds. Gene 1995, 156:119-122.

73. de Kok S, Yilmaz D, Suir E, Pronk JT, Daran JM, van Maris AJ: Increasing free-energy (ATP) conservation in maltose-grown Saccharomyces cerevisiae by expression of a heterologous maltose phosphorylase. Metab Eng 2011, 13:518-526.

74. Yamada K, Lim J, Dale JM, Chen H, Shinn P, Palm CJ, Southwick AM, Wu HC, Kim C, Nguyen M, et al: Empirical analysis of transcriptional activity in the Arabidopsis genome. Science 2003, 302:842-846.

75. Seki M, Narusaka M, Kamiya A, Ishida J, Satou M, Sakurai T, Nakajima M, Enju A, Akiyama K, Oono Y, et al: Functional annotation of a full-length Arabidopsis cDNA collection. Science 2002, 296:141-145.

76. Gietz RD, Schiestl RH: High-efficiency yeast transformation using the LiAc/SS carrier DNA/PEG method. Nat Protoc 2007, 2:31-34.

77. Noskov VN, Koriabine M, Solomon G, Randolph M, Barrett JC, Leem SH, Stubbs L, Kouprina N, Larionov V: Defining the minimal length of sequence homology required for selective gene isolation by TAR cloning. Nucleic Acids Res 2001, 29:E32. 
78. Grote A, Hiller K, Scheer M, Munch R, Nortemann B, Hempel DC, Jahn D: JCat: a novel tool to adapt codon usage of a target gene to its potential expression host. Nucleic Acids Res 2005, 33:W526-W531.

79. Watts KT, Mijts BN, Lee PC, Manning AJ, Schmidt-Dannert C: Discovery of a substrate selectivity switch in tyrosine ammonia-lyase, a member of the aromatic amino acid lyase family. Chem Biol 2006, 13:1317-1326.

80. De Vos RC, Moco S, Lommen A, Keurentjes JJ, Bino RJ, Hall RD: Untargeted large-scale plant metabolomics using liquid chromatography coupled to mass spectrometry. Nat Protoc 2007, 2:778-791.

doi:10.1186/1475-2859-11-155

Cite this article as: Koopman et al: De novo production of the flavonoid naringenin in engineered Saccharomyces cerevisiae. Microbial Cell Factories 2012 11:155.

\section{Submit your next manuscript to BioMed Central and take full advantage of:}

- Convenient online submission

- Thorough peer review

- No space constraints or color figure charges

- Immediate publication on acceptance

- Inclusion in PubMed, CAS, Scopus and Google Scholar

- Research which is freely available for redistribution 